\title{
Afiliação com pares sócio-normativos e condutas desviantes
}

\author{
Affiliation with socio-normative pair and deviant conduct
}

Nilton Soares Formiga ${ }^{1}$

\begin{abstract}
RESUMO
Neste trabalho pretende-se avaliar o poder preditivo entre a afiliação com os pares sócio-normativos e as condutas anti-sociais e delitivas. Na Busca em responder as causas das condutas permeadoras da delinquência entre jovens, a família e a escola têm se preocupado quanto aos fatores de proteção entre eles. Três amostras com jovens entre 15 e 21 anos e ambos os sexos, da cidade João Pessoa -PB e Palmas - TO foram utilizadas. Estes responderam a Escala de Condutas Anti-sociais e Delitivas e da Identidade com pares sócio-normativos. Em todas as amostras, esses pares (pai, mãe e professor) foram capazes de predizer tanto a conduta anti-social quanto delitiva. Desta forma, quanto maior a identidade que esses jovens possam ter, com cada par social, maior a probabilidade de inibir as condutas permeadoras da delinquência.
\end{abstract}

Palavras-Chave: Pares; Condutas anti-sociais e delitivas; Jovens; Predição.

\section{ABSTRACT}

Seeking to answer the causes of interposed behaviors of delinquency among young people, family and school, besides be worried about this problem, has interested to studious as a protective factor that these institutions can offer to young people facing. This work aims to assess the predictive power between the affiliation with socialnormative pair and the anti-social and criminal conducts in different samples. Three samples with young people between 15 and 21 years old, men and women, in the cities of João Pessoa-PB and Palmas - TO be used. They answered the Scale of Anti-social and criminal conducts and the Identity with socio-normative pair. In all samples, the socio-normative pairs (father, mother and teacher) predicted both the anti-social as criminal conducts. How bigger is the identity that these young people have with each social pairs more is the probability to inhibit the interposed conduct of delinquency.

Key-words: Anti-social and criminal conducts; Family; School; Young people.

\footnotetext{
${ }^{1}$ Mestre em psicologia social pela universidade Federal da Paraíba; atualmente é doutorando na mesma universidade.
} 


\section{INTRODUÇÃO}

Compreender as causas dos comportamentos desviantes entre os jovens, além de não ser algo novo, permite apontar em direção de intervenções psicossociais e políticas públicas capazes de inibir uma maior desorganização na sociedade entre eles. Sejam aquelas explicações que visem uma perspectiva mais individual - sócio-demográfica e personalística - ou aquelas que promovam a compreensão de uma dimensão mais ampla e dinâmica - sistema e estrutura familiar, valores humanos, etc. - todas elas buscam responder quais variáveis influenciam o jovem a manifestar uma conduta que tangencie as normas socialmente desejáveis: os comportamentos desviantes. (AGÜERO, 1998; FORMIGA et al, 2003; MUÑOZ, NAVAS \& GRAÑA, 2005; STOFF; BREILING; MASER, 1997; SUKHODOLSKY; COLUB; CROMWELL, 2001).

Mesmo que exista inúmeras variáveis que expliquem esses comportamentos desviantes entre os jovens, a família, apesar de se apontar para existência de uma fissura que esta instituição tem apresentado atualmente, no que diz respeito ao apoio para a responsabilidade e promoção de comportamentos sociais das pessoas que a compõem, seja em sua perspectiva estrutural ou funcional, ela ainda vem manifestando interesse aos pesquisadores (BRENNER; FOX, 1998; BOLSONISILVA; MARTURANO, 2002; FORMIGA; OLIVEIRA; CURADO; LÜDKE; TEIXEIRA; FACHINI, 2003). Tal condição se deve a busca de se compreender os construtos psicossociais nas relações entre as pessoas da família (por exemplo, atitudes, personalidade, motivação, valores, etc.), a sociedade contemporânea e sua influência entre os jovens e suas condutas sociais, especialmente, as condutas desviantes.

Vale destacar que o problema da conduta desviante, ultimamente, não tem autor e rótulo específico, mas condutas de risco bastante evidentes as quais podem se apresentar com uma conduta anti-social e/ou delitiva (FORMIGA; GOUVEIA, 2003). A conduta anti-social refere-se a não conscientização das normas que devem ser respeitadas - desde a norma de limpeza das ruas ao respeito com os colegas no que se refere a certas brincadeiras - e não praticadas por alguns jovens. Neste sentido, este tido de conduta caracteriza-se pelo fato de incomodarem, mas sem que causarem necessariamente danos físicos a outras pessoas; elas dizem respeito 
apenas às travessuras dos jovens ou simplesmente à busca de romper com algumas leis sociais (FORMIGA; GOUVEIA, 2003).

Em relação à conduta delitiva, esses autores, concebem-na como merecedoras de punição jurídica, capazes de causar danos graves, morais e/ou físicos. Portanto, tais condutas podem ser consideradas mais severas que as anteriores, representando uma ameaça eminente à ordem social vigente. $\mathrm{O}$ que essas condutas têm em comum é que ambas interferem nos direitos e deveres das pessoas, ameaçando o seu bem-estar, bem como, diferenciando-as em função da gravidade das consequências oriundas. (FORMIGA; GOUVEIA, 2003; ESPINOSA, 2000; MOLINA \& GÓMEZ, 1997). Possivelmente, todo jovem pratica ou já praticou algum tipo de conduta anti-social, o que faz parte do repertório deles, salientando como um desafio dos padrões tradicionais da sociedade, pondo em evidência as normas da geração dos seus pais.

A preocupação que se tem com a família e sua dinâmica, atualmente, diz respeito a formação e socialização valorativa que os jovens e adultos, incluso e ativo nesta instituição, são capazes de transmitir e auto-transmitirem, tanto na sua internalidade quanto externalidade, uma condição psicossocial do valor das outras pessoas e suas condutas frente a elas, inibindo as condutas de risco. Mas, o que é mais significativo para uma boa relação sócio-familiar?

É frente a esse questionamento que Formiga, Gouveia, Andrade, Pimentel, Santos e Sousa (2003) procuraram responder; para esses autores, a dinâmica do relacionamento familiar é um fator importante na vida do adolescente, pois tem uma influência direta na formação do comportamento social e psicológico deles. Afinal, é sobre essa funcionalidade que 0 aprendizado desses jovens quanto ao comportamento socialmente desejável não apenas revela a estrutura familiar, mas também, o quanto se é capaz de contribuir para um fator de inibição em relação a quebra de normas sociais entre os pares de iguais.

O valor da relação familiar é tão importante, que mesmo na fase da adolescência, momento de expressiva necessidade de autonomia para o jovem frente aos laços familiares e suas exigências, não é dissolvido com facilidade; bem como, o seguimento de uma norma socializada internamente entre os membros que 
a compõem, a qual contribui para o bem-estar psicológico dos jovens e estabilidade sócio-emocional de seu ambiente familiar e interpessoal (BEE, 1997; FORMIGA, 2004; OUTEIRAL, 1994).

Assim, a família como o primeiro grupo em a pessoa é capaz de receber uma formação individual e social (ARIÉS, 1981) promovendo a internalização, manutenção e transmissão moral e valorativa alicerçando no transcorrer de sua vida juvenil para adulta ações socialmente aceitas (FORMIGA et al, 2003; SCHNEIDER, 2001). Com isso, a família é "uma forma básica de ajuda mutua e suporte material e emocional, local para nutrir e criar as gerações futuras" (DOMINGUES, 2002, p. 92).

Apesar do interesse sobre a influência estrutural e funcional da família sobre as condutas dos jovens nas relações interpessoais (GROSSI et al, 2004; TORRENTE; RODRIGUEZ, 2000), no Brasil ainda são poucos estudos que tem se concentrado na identidade com os pares normativos e a relação com as condutas juvenis. A fim de aferir essa situação, em recente pesquisa realizada nos sites de busca de periódicos brasileiros com as combinações de palavras-chave: Família, organização, conduta, jovens e Conduta, jovens, família, estrutura e família, sociedade e delinqüência (INDEX PSI, 2008; SCIELO, 2008) encontrou-se apenas um trabalho desenvolvido por Formiga e Fachini (2003) e Formiga (2005) sobre esse aspecto:

1 - No estudo realizado por Formiga e Fachini (2003) buscava-se avaliar a relação do que eles chamaram de identificação com endogrupos diários (por exemplo, família, familiares, vizinhos, amigos e professores) e a conduta desviante. Esses autores observaram em amostras sócio-demograficamente diferentes que os endogrupos família, familiares e professores se relacionaram negativamente com as condutas desviantes; por outro lado, os vizinhos não houve relação, e os amigos e colegas relacionaram positivamente com as mesmas condutas. Mesmo que o estudo desses autores traga resultados satisfatórios, uma crítica pode ser apontada quanto a variável da identificação endogrupal.

Ao considerar essa quantidade de endogrupos parece haver uma inconsistência entre a perspectiva teórica e empírica; afinal alguns dos grupos inseridos no estudo de Formiga e Fachini (2003) têm maior poder de influência na 
conduta socialmente desejável, bem como, intervenção direta na conduta juvenil. Assim, os autores resolveram reduzir esses endogrupos e a partir da base teórica que sustentava o trabalho deles (ver BOLSONI-SILVA; MARTURANO, 2002; BRONFENBRENNER, 1994/1996) resolveram assumir o construto como identificação com os pares sócio-normativos, isto é, aqueles pares que são responsáveis e atuam diretamente pelo estabelecimento e manutenção das condutas normativas dos jovens na sociedade (por exemplo, o pai, mãe e professor), condição essa, desenvolvida no trabalho de Formiga (2005).

2 - Formiga (2005), ao considerar as reflexões elaboradas por Formiga e Fachini (2003), retomou o estudo e, de forma parcimoniosa, hipotetizou que daqueles inúmeros grupos sociais que os jovens interagem com o objetivo de controlar um comportamento socialmente desejável, os que podem ser mais influentes seriam a família e a escola. No primeiro, estariam os pais (pai e mãe ou um deles) e no segundo, o professor. Desta maneira, Formiga (2005) observou que quanto maior a identificação do jovem com esses pares (pai, mãe e professor) será menor a pontuação na conduta anti-social e delitiva.

Concretamente, ao se investir na identidade com esses pares e sua influência nas condutas em jovens, principalmente, em relação às anti-sociais e delitivas, enfatiza-se o quanto o jovem, em termos afetivos, se assemelha com essas pessoas em seu cotidiano, já que estes são objetos humanos que procuram dar seguimento a uma formação valorativa, sugerindo com isso, uma conduta social adequada. (FORMIGA, 2005). Alguns estudos, mesmo utilizando diferentes variáveis, mas, tem focalizando os mesmos objetivos desenvolvidos no presente estudo, por exemplo, Muñoz-Rivas e Graña (2001), além de considerar a estrutura familiar e sua influência no consumo de drogas lícitas e ilícitas incluíram uma variável sobre relações afetivas com os pais e observaram que quanto maior o vínculo afetivo do jovem com o pai e a mãe, maior a capacidade de inibir a conduta consumista de drogas.

Outros estudos, próximos ao de Formiga (2005) e Muñoz-Rivas e Graña (2001), foi desenvolvido por Villar, Luengo, Gómez e Romero (2003) ao explicarem, também, a conduta de drogadição; destacaram que a escassez afetiva entre pais e filhos não é somente um fator de risco no uso dessas substâncias e da conduta 
delitiva, mas também, influencia o sujeito a uma baixa estima e mau rendimento escolar. Na mesma direção Hein (2004) observou que os jovens que apresentaram baixa coesão familiar, parentalidade coercitiva e permissiva e baixo apoio do professor estavam ligados a condutas desviantes. Mesmo utilizando outros instrumentos que avaliavam a dinâmica familiar e a relação com as condutas desviantes, Rodríguez e Torrente (2003) observaram que o clima familiar com coesão interna, por exemplo, laços emocionais fortes e diálogo entre os membros da família, atividades sócio-recreativa e moral-religiosa, além de contribuir como fator de proteção da conduta desviante, sustenta um desenvolvimento do auto-conceito e auto-estima. Com isso, para Rodríguez e Torrente (2003; MUÑOZ, NAVAS, GRAÑA, 2005; MUÑOZ, 2004) o foco nestas variáveis que avaliam o espaço e a dinâmica familiar favorece a adaptação social e permite a transmissão de padrões e normas culturais dos pais para os filhos.

Outro trabalho que enfatiza semelhantes variáveis foi desenvolvido por Grossi et al. (2004); eles apontaram que o laço afetivo e boa comunicação entre pai e filho são capazes de manter uma relação familiar que satisfaça as necessidades dos membros em diferentes fases de seu desenvolvimento contribuindo na prevenção de futuros comportamentos permeadores da delinqüência. Esses autores comprovaram essa hipótese quando estudaram 87 jovens que estavam num centro penitenciário de Villabona na Espanha, onde observaram que os jovens que estavam detidos neste centro apresentaram em sua família mal-trato, déficits nas relações afetivas e baixo nível de comunicação. Sobre esse construto, segundo Avellar (2007), é de extrema importância, pois, o papel dos compromissos sociais do direito e costumes, interiorização das normas e valores somente é possível a partir do processo de socialização desenvolvido pelas diversas instituições sociais tendo a família a instituição mais responsável por isso; bem como, pela transmissão e difusão de padrões culturais em relação à geração posterior, contribuindo para exposição de protótipos sociais influenciadores do comportamento e das conversações casuais orientadas pelos pais, os quais são inibidores da conduta desviante.

Ao considerar a identidade que os jovens venham a ter com esses pares pretende-se contribuir não apenas com a inibição das condutas delinquentes, mas, em direção de um melhor desenvolvimento psicossocial juvenil. Fato esse, que segundo Mulvey e Cauffman (2001), os jovens, apesar de avançarem no 
desenvolvimento em termos da formação das diferenças individuais, estas, ainda não são totalmente formadas, impedindo avaliar a rápida mudança da sua conduta e interação com as pessoas de sua convivência, interferindo na formação de habilidades sociais e comportamento socialmente desejável.

Sendo assim, é necessária a elaboração de estratégias que coloquem escola, família e comunidade em programas contra a delinqüência já que são espaços institucionais responsáveis por uma formação contínua do comportamento social e interpessoal. O qual se não de forma dialógica, através do controle, construto esse, que segundo Bates, Bader e Mencken (2003), também, contribuiriam para as explicações sobre as diferenças de gênero, idade e classe social em relação ao crime, bem como, a probabilidade da motivação as atitudes de correr riscos, consecutivamente, ao desvio.

De forma geral, para Bates, Bader e Mencken (2003) o poder de controle, bem como, do diálogo por parte da família é suposto constituinte dos agentes da socialização na família, sendo esse controle, capaz de inibir as condutas permeadores da delinqüência entre os jovens membros das famílias. Por fim, com o estudo desses autores é possível refletir, não somente a capacidade parental de diálogo, mas também, no investimento no processo de monitoramento das condutas juvenis por parte das famílias. Com isso, partindo desse pressuposto e com base nos estudos de Formiga (2005), espera-se que: 1- a identidade com os pares sócionormativos (especificamente, com o pai, a mãe e o professor) apresente um poder preditivo $^{2}$, negativo, em relação a conduta anti-social e delitiva e 2- espera-se também, que a identidade entre os pares (pai, a mãe e professor) estejam interrelacionadas.

\section{MÉTODO}

\section{Amostra}

Três amostras compostas por jovens, com idades entre 15 e 21 anos, do sexo masculino e feminino, das cidades de João Pessoa compuseram o estudo. Todas

\footnotetext{
${ }^{2}$ Ao considerar o poder preditivo em uma pesquisa faz-se referência ao cálculo da análise de regressão. Esse cálculo estatístico visa, a partir de seus indicadores psicométricos, prever uma relação funcional entre as variáveis independentes sobre as dependentes, ao invés da relação causa e efeito proposto pela correlação de Pearson; condição essa que, partindo desse cálculo, pretende-se elaborar um modelo teórico.
} 
elas foram distribuídas igualmente nos nível escolar fundamental e médio da rede privada e pública de educação da cidade. Na primeira amostra $\left(\mathbf{N}_{1}\right) 489$ sujeitos, entre 15 e 20 anos, predominando ligeiramente a participação das mulheres (52\%) e com renda econômica superior a $\mathrm{R} \$ 660,00$; a segunda amostra $\left(\mathbf{N}_{\mathbf{2}}\right)$ foi composta de 530 sujeitos, entre 16 a 21 anos, com uma distribuição eqüitativa em relação ao gênero e uma rende econômica de, aproximadamente, $\mathrm{R} \$ 545,00$; por fim, na terceira amostra $\left(\mathbf{N}_{3}\right)$ com 400 sujeitos, entre 15 a 20 anos, com $57 \%$ eram mulheres, e com uma renda econômica de $\mathrm{R} \$ 722,00$.

Tal amostra foi não probabilística e, sim, intencional; pois além do propósito de garantir a validade interna dos instrumentos da pesquisa, era assegurada a possibilidade de realizar as análises estatísticas que permitissem estabelecer os critérios preditivos entre as variáveis estudadas.

\section{Instrumentos}

Os participantes responderam um questionário composto das seguintes medidas:

Escala de Condutas Anti-sociais e Delitivas. Este instrumento, proposto por Seisdedos (1988) e validado por Formiga e Gouveia (2003) para o contexto brasileiro, compreende em uma medida comportamental em relação às $\underline{\text { Condutas }}$ Anti-Sociais e Delitivas. Tal medida é composta por quarenta elementos, distribuídos em dois fatores, como segue: condutas anti-sociais. Seus elementos não expressam delitos, mas comportamentos que desafiam a ordem social e infligem normas sociais (por exemplo, jogar lixo no chão mesmo quando há perto um cesto de lixo; tocar a campainha na casa de alguém e sair correndo); e condutas delitivas. Estas incorporam comportamentos delitivos que estão fora da lei, caracterizando uma infração ou uma conduta faltosa e prejudicial a alguém ou mesmo a sociedade como um todo (por exemplo, roubar objetos dos carros; conseguir dinheiro ameaçando pessoas mais fracas). Para cada elemento, os participantes deveriam indicar o quanto apresentavam o comportamento assinalado no seu dia a dia. Para isso, utilizavam uma escala de resposta com dez pontos, tendo os seguintes extremos: $\mathbf{0}$ = Nunca e $\mathbf{9}=$ Sempre. 
A escala revelou indicadores psicométricos consistentes identificando os fatores destacados acima; para a Conduta Anti-social foi encontrado alpha de cronbach de 0,86 e a Conduta Delitiva ou Delinqüente, 0,92. Considerando a Análise Fatorial Confirmatória, realizada com o Lisrel 8.0, comprovou-se essas dimensões previamente encontradas $\left(\chi^{2} / \mathrm{gl}^{3}=1,35 ; A G F I^{4}=0,89 ; \mathrm{PHI}(\phi)^{5}=0,79, p>0,05\right)$ na análise dos principais componentes (FORMIGA; GOUVEIA, 2003). Os indicadores de qualidade de ajuste do modelo se mostraram próximos aos recomendados apresentados na literatura (Byrne, 1989; Tabachnick \& Fidell, 1996; van de Vijver \& Leung, 1997)

Questionário da identidade com pares sócio-normativos. Desenvolvido por Formiga (2005), nesse instrumento o sujeito era orientado a responder as questões referidas a sua identificação com os pares responsáveis pela socialização do comportamento socialmente aceito, considerando-os como pares sócio-normativos; isto é, eles deveriam assinalar, marcando com um círculo ou $\mathbf{X}$ numa escala de cinco pontos, tipo Likert, que variava de $\mathbf{0}=$ Não me Identifico totalmente a $\mathbf{5}=$ Identificome totalmente, o quanto o jovem se assemelhava a cada um dos pares sócionormativos referidos no questionário (por exemplo, o quanto eles se identificavam com o pai, a mãe e o professor). Para isso, deveriam ter como foco a contribuição que cada um deles, de forma contínua, tem para sua formação social e afetiva em sua vida cotidiana.

Caracterização Sócio-Demográfica. Foram elaboradas perguntas que contribuíram para caracterizar os participantes deste estudo (por exemplo, sexo, idade, estado civil, classe social).

\section{Procedimento}

Para a aplicação do instrumento, o responsável pela coleta dos dados visitou a coordenação ou diretoria das instituições de ensino, falando diretamente com os diretores e/ou coordenadores para depois buscar a permissão junto aos professores responsáveis por cada disciplina, para ocupar uma aula e aplicar os questionários. Uma vez com tal autorização foi exposto sumariamente o objetivo da pesquisa,

\footnotetext{
${ }_{4}^{3} x^{2} / g l=$ razão qui-quadrado $/$ graus de liberdade

${ }^{4}$ AGFI = Adjusted Goodness of Fit Index

${ }^{5} \mathrm{PHI}(\phi)=$ livre a covariância; indicando a relação entre os fatores
} 
solicitando sua participação voluntária. Um único aplicador, previamente treinado, esteve presente em sala de aula. Sua tarefa consistiu em apresentar os instrumentos, solucionar as eventuais dúvidas e conferir a qualidade geral das respostas emitidas pelos respondentes. Assegurou-se a todos o anonimato e a confidencialidade das suas respostas, indicando que estas seriam tratadas estatisticamente no seu conjunto.

\section{Tabulação e Análise dos Dados}

Para a análise dos dados foi utilizado o pacote estatístico SPSSWIN em sua versão 11.0 onde foram efetuadas análises descritivas (medida de dispersão e tendência central) e computadas correlações de Pearson (ํ) e efetuadas análise de regressão $(\beta)$.

\section{RESULTADOS E DISCUSSÃO}

Antes de atender o objetivo principal desse estudo, bem como, a proposição da primeira hipótese a ser testada, efetuando uma análise de regressão para ela, resolveu avaliar as correlações internas entre a identidade com os pares sócionormativos e a conduta anti-social e delitiva. Assim, na tabela 1, pode ser observado que, em todas as três amostras, houve uma relação direta e significativa entre a conduta anti-social, delitiva e desviante (esta se refere ao somatório geral dos itens da escala).

No que diz respeito às correlações encontradas entre as condutas é destaque que o indivíduo que apresente uma conduta anti-social, provavelmente, apresentará conduta delitiva. Além dos resultados corroborar o estudo de Formiga (2002) e Formiga (2003) quanto as relações positivas entre essas condutas, permite refletir em relação a perspectiva teórica de Moffitt (BUCETA, 2000); este autor, defende que na adolescência existe uma delinqüência persistente e limitada a que todo jovem está susceptível. Sendo assim, quanto maior for a conduta anti-social (a delinqüência persistente) e mais longa a manutenção desta, maior a probabilidade de que elas permaneçam ao longo da vida, convergindo para uma conduta delitiva. Essa condição comportamental incorporada na vida social juvenil pode até não prejudicar fisicamente - apesar de incomodar muito - os outros tornando como parte da dinâmica desenvolvimentista e psicossocial do adolescente justificada como parte 
do seu neuro-psicologismo ou fisiologismo, mas que, é susceptível a intervenção e controle. Quando não inibida, seja pelo controle das instituições ou pares de iguais, tende a decorrer numa conduta delitiva.

Tabela 1: Correlação interna entre as condutas anti-social, delitiva e conduta desviante nas três amostras.

\begin{tabular}{|c|c|c|c|c|c|c|c|c|c|}
\hline & & \multicolumn{3}{|l|}{ N1 } & \multicolumn{2}{|l|}{ N2 } & & \multicolumn{2}{|l|}{ N3 } \\
\hline \multicolumn{10}{|c|}{ - - - - - - - - - - - - - - - - - - - - - - - - - - - - - - - - - - } \\
\hline & 1 & 2 & 3 & 1 & 2 & 3 & 1 & 2 & 3 \\
\hline Conduta anti-social & 1,00 & $0,62^{*}$ & $0,97^{*}$ & 1,00 & $0,65^{*}$ & $0,95^{*}$ & 1,00 & $0,60^{*}$ & $0,92^{*}$ \\
\hline Conduta delitiva & & 1,00 & $0,74^{*}$ & & 1,00 & $0,77^{*}$ & & 1,00 & $0,72^{*}$ \\
\hline Conduta desviante $e^{\#}$ & & & 1,00 & & & 1,00 & & & 1,00 \\
\hline
\end{tabular}

Notas: * $\underline{p}<0,001$. Teste unilateral e eliminação pairwise de casos em branco. \# Conduta desviante = somatório total dos itens da escala.

Assim realizado, procurou-se seguir semelhante direção para a variável identificação com os pares sócio-normativos; na tabela 2, estão os resultados da correlação interna. É possível observar que nas três amostras os pares sócionormativos se correlacionaram entre si. A identidade que o jovem tem com o pai se relacionou, positiva e significativamente, com a mãe, e estes, com o professor. Atendido a etapa das inter-correlações, a seguinte etapa tratou-se de avaliar os critérios preditivos entre os pares sócio-normativos e as condutas desviantes, objetivo central do presente estudo. 
Tabela 2. Correlações internas entre pares sócio-normativos nas três amostras.

\begin{tabular}{|c|c|c|c|c|c|c|c|c|c|}
\hline \multirow[b]{2}{*}{ Pares sócio-normativos } & \multicolumn{3}{|c|}{ N1 } & \multicolumn{2}{|r|}{ N2 } & \multicolumn{4}{|c|}{ N3 } \\
\hline & 1 & 2 & 3 & 1 & 2 & 3 & 1 & 2 & 3 \\
\hline Pai & 1,00 & $0,38^{*}$ & $0,17^{*}$ & 1,00 & $0,35^{*}$ & $0,20^{*}$ & 1,00 & $0,33^{*}$ & $0,20^{*}$ \\
\hline Mãe & & 1,00 & $0,15^{*}$ & & 1,00 & $0,13^{*}$ & & 1,00 & $0,18^{*}$ \\
\hline Professor & & & 1,00 & & & 1,00 & & & 1,00 \\
\hline
\end{tabular}

Notas: * $p<0,001$ (teste unilateral; eliminação pairwise de casos em branco).

Desta forma, a partir da análise de regressão, na tabela 3 é apresentado os betas regressivos dos pares sócio-normativos em relação as condutas desviantes; estes foram capazes de predizer estas condutas (anti-social, delitiva e desviante) entre os jovens nas três amostras, mantendo com isso, não somente a segurança preditiva entre as variáveis, resultado já encontrado por Formiga (2005), bem como, apresentando um poder preditivo, negativo, das variáveis que avaliam as condutas permeadoras da delinqüência em diferentes amostras.

Especificamente, na amostra N1, com 489 sujeitos, a identidade com o pai aponta, negativamente, para a conduta anti-social $(F[3 / 450]=14,09, p<0,001$; $\left.R_{\text {múltiplo }}=0,09, R_{\text {ajustado }}=0,08\right)$ e delitiva $\left(F[3 / 458]=8,97, p<0,001 ; R_{\text {múltiplo }}=0,06\right.$, $\left.\mathrm{R}^{2}{ }_{\text {ajustado }}=0,05\right)$, da mesma forma a identidade com a mãe e o professor apresenta beta regressivo negativo. $\mathrm{O}$ mesmo foi observado na amostra N2, com 530 jovens, os resultados foram semelhantes: a identidade com o pai, mãe e professor, apresentaram betas regressivos negativos, tanto para a conduta anti-social ( $F$ $\left.[3 / 494]=9,29, p<0,001 ; R_{\text {mútiplo }}=0,05, R_{\text {ajustado }}=0,05\right)$ quanto a delitiva $(F[3 / 484]$ $\left.=8,11, p<0,001 ; R_{\text {mútiplo }}=0,05, R_{\text {ajustado }}=0,04\right)$. Por fim, a amostra N3, com 400 jovens, apresentou também, semelhantes resultados: a identidade com o pai, a mãe e o professor foi capaz de predizer, negativamente, a conduta anti-social $(F[3 / 377]=$ $\left.7,55, p<0,001 ; R_{\text {múltiplo }}=0,06, R_{\text {ajustado }}=0,05\right)$ e delitiva $(F[3 / 383]=6,75, p<$ 0,$\left.001 ; R_{\text {múltiplo }}=0,05, R_{\text {ajustado }}=0,04\right)$. 
Tabela 3. Análise Regressão para as condutas anti-sociais e delitivas, tendo como preditoras a identidade com os pares sócio-normativos entre as três amostras.

\begin{tabular}{|c|c|c|c|c|c|c|}
\hline Condutas & Preditoras & & B & & $t$ & \\
\hline---------- & 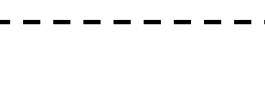 & $\bar{N}_{1}^{-}$ & $-\overline{N_{2}}-$ & $\overline{\mathbf{N}}_{3}^{-}$ & $\bar{N}_{1}^{--} \bar{N}_{2}^{-}$ & $\overline{N_{3}}-----$ \\
\hline \multirow[t]{3}{*}{ Anti-Sociais } & Pai & $-0,12$ & $-0,10$ & $-0,10$ & $-2,31^{*}-1,48^{*}$ & $-3,04^{*}$ \\
\hline & Mãe & $-0,10$ & $-0,11$ & $-0,10$ & $-1,68^{*}-1,56^{*}$ & $-1,84^{*}$ \\
\hline & Professor & $-0,20$ & $-0,16$ & $-0,14$ & $-4,26^{*}-3,03^{*}$ & $-1,87^{*}$ \\
\hline \multirow[t]{3}{*}{ Delitivas } & Pai & $-0,10$ & $-0,11$ & $-0,10$ & $-1,62^{*}-1,58^{*}$ & $-1,46^{*}$ \\
\hline & Mãe & $-0,11$ & $-0,15$ & $-0,17$ & $-2,16^{*}-2,58^{*}$ & $-3,48^{*}$ \\
\hline & Professor & $-0,18$ & $-0,14$ & $-0,11$ & $-3,76^{*}-2,73^{*}$ & $-2,47^{*}$ \\
\hline Condutas $^{\#}$ & Pai & $-0,11$ & $-0,10$ & $-0,10$ & $-2,10^{*}-1,68^{*}$ & $-1,72^{*}$ \\
\hline \multirow[t]{2}{*}{ Desviantes (CAD) } & Mãe & $-0,10$ & $-0,10$ & $-0,13$ & $-1,80^{*}-1,71^{*}$ & $-2,54^{*}$ \\
\hline & Professor & $-0,21$ & $-0,17$ & $-0,15$ & $-4,50^{*}-3,38^{*}$ & $-3,29 *$ \\
\hline
\end{tabular}

Notas: * $p<0,01$; \# CAD = Pontuação total das condutas anti-sociais e delitivas. $\mathrm{N}_{1}=$ Amostra com 489 sujeitos, $\mathrm{N}_{2}=$ Amostra com 530 sujeitos e $\mathrm{N}_{3}=$ Amostra com 400 sujeitos.

Nas três amostras, há um poder preditivo negativo dos chamados pares sócio-normativos em relação às condutas desviantes, revelando-se como fator de proteção frente aos jovens; isto é, quanto maior a identidade com esses pares, menor a conduta desviante. Outro destaque, diz respeito a relação entre esses pares, apresentado na tabela 2, destacando a existência de uma espécie de sistema entre eles que, provavelmente, garantiriam um retorno ao diálogo entre eles, sua interação social e sua condição de transmitir e orientar os jovens a uma conduta socialmente desejável.

Sendo assim, uma maior identidade com esses pares, provavelmente, seria capaz de inibir condutas que tangenciam as normas sociais, revelando o quanto esses jovens se expressariam afetiva, motivacional e comportamentalmente em 
direção de cada par sócio-normativo, considerando-se nesse conjunto identitário a probabilidade de que um evento social e psicológico se estabeleça como fator de proteção da conduta delinqüente a partir da relação dos jovens com o pai, a mãe e o professor.

Como dado adicional, a partir de uma análise descritiva (Média e Desvio Padrão), observou-se (ver gráfico 1) uma hierarquia identitária para esses jovens em relação aos pares sócio-normtaivos nas três amostras: a mãe apresentou média superior $\left(M_{N 1}=4,75 ; D P=1,15 ; M_{N 2}=5,25 ; D P=0,80 ; M_{N 3}=4,35 ; D P=1,07\right)$, seguido pelo pai $\left(M_{N 1}=4,15 ; \mathrm{DP}=0,97 ; \mathrm{M}_{\mathrm{N} 2}=5,10 ; \mathrm{DP}=1,30 ; \mathrm{M}_{\mathrm{N} 3}=3,97 ; \mathrm{DP}=\right.$ $1,24)$, o qual teve média superior em relação ao professor $\left(M_{N 1}=3,02 D P=0,85\right.$; $\left.M_{N 2}=2,90 ; D P=1,12 ; M_{N 3}=2,00 ; D P=0,75\right)$. Além desses pares - pai, mãe e professor - se relacionarem diretamente entre si (ver tabela 2), os quais correlacionaram, negativamente, com a conduta anti-social e delitiva existe, hierarquicamente, uma contribuição para construção de fatores de apoio sóciopsicológico entre os jovens quanto ao critério de identificação sócio-afetiva. Por exemplo, primeiro a mãe, em seguida, o pai, posteriormente, o professor, mantendo a existência do compromisso convencional.

Parece existir um "efeito dominó" positivo na orientação das condutas normativas para esses jovens entre os pares e as práticas sócio-normativas. Esse fato, permite refletir em relação a condição do papel da família e escola não formação e transmissão de padrões sociais e humanos para os jovens e que, ao considerar esses resultados, é possível refletir no apoio social e importância dessas instituições para intervenção dos comportamentos desviantes. 
Gráfico 1: Análise descritiva da pontuação média das respostas dos jovens em relação aos pares sócio-normativos.

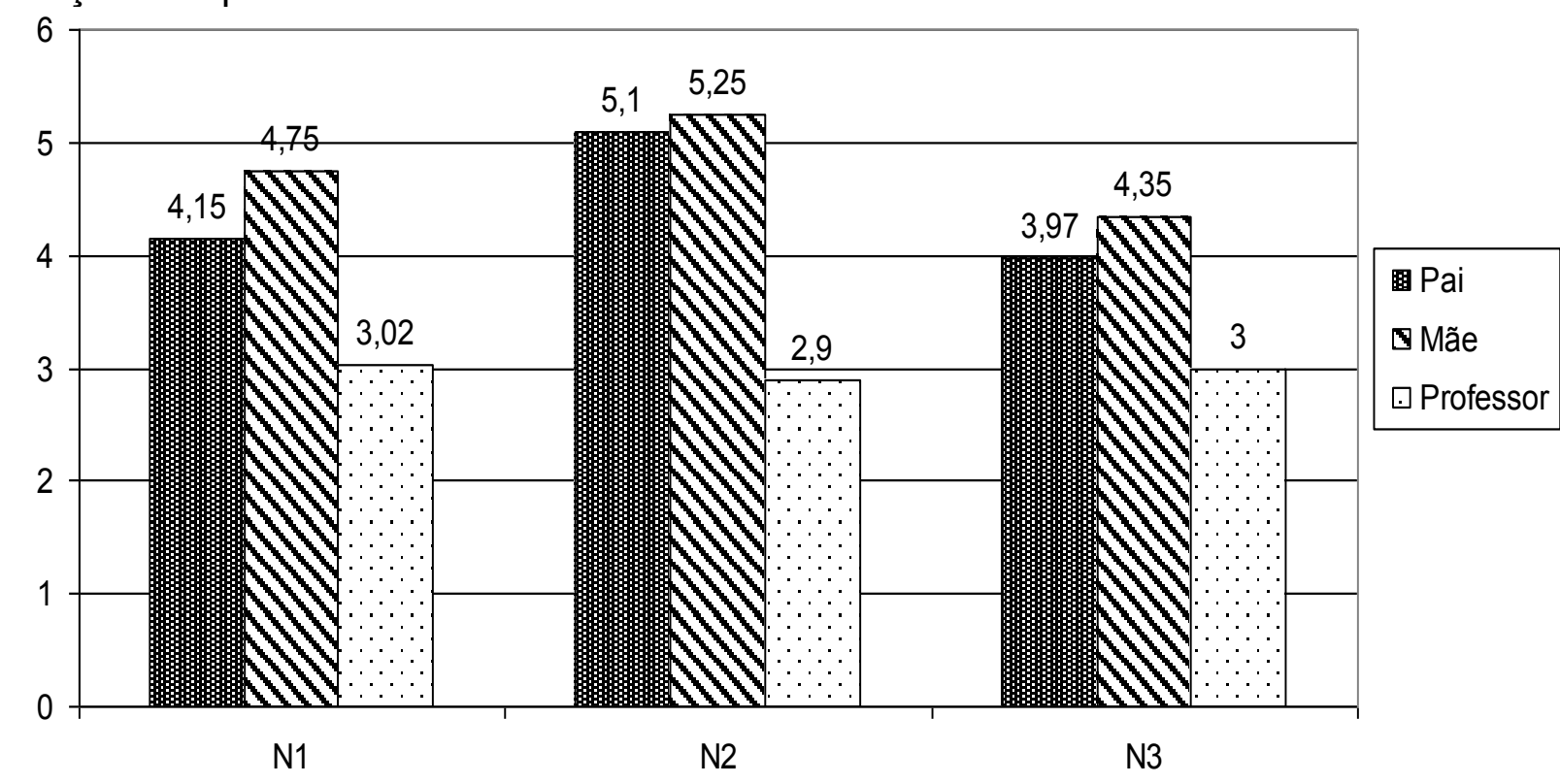

Observando esses resultados é possivel afirmar que não somente as hipóteses formuladas foram confirmadas, mas que, elas corroboram o estudo de Formiga (2005); ao considerar que os jovens deveriam apresentar uma conduta socialmente desejável e que isso não acontece de forma isolada, e muito menos, sob um discurso da liberdade expandida experimentando a tudo que the vier ao pensamento e vontade (FORMIGA, 2008); os pares sócio-normativos podem ser caracterizados como um continuum formador para a conduta juvenil normativa, colaborando para a manutenção das normas sociais. Neste caso, pais e professores, apontam para uma consonância ao compromisso convencional, tornando-os como fatores de proteção para os jovens.

Afinal, não somente esses pares estariam inter-relacionados (ver tabela 2) mostrando que o discurso cotidiano em que família e escola podem trabalhar em conjunto para inibir diversos fenômenos sociais, especialmente, a conduta desviante, neste trabalho pode ser vislumbrado uma resposta para isso. Essa convergência entre a identidade desses pares (inter-relações entre pai, mãe e professores) pode contribuir para programas de intervenção das condutas antisociais e delitivas apontando para uma aplicação sistêmica, onde professor e família trabalhassem paralelamente na orientação dos seus adolescentes. Mas como isso seria possível, já que os jovens não vivem tempo integral na escola para que possa 
observar seus comportamentos? O fato é que, por existir algumas condutas não observadas pelos pais durante o período que esses jovens passam na escola, 0 professor poderá observá-las e junto a família promover atitudes que seguem e influenciam uma formação moral e valorativa preconizada por essas instituições. Desta maneira, a orientação não estaria apenas em uma direção ideológica de cada instituição, mas, visando uma invenção psicossocial frente ao não cumprimento das condutas socialmente aceitas.

A explicação da conduta anti-social e delitiva no presente estudo evidencia a não observância das normas e regras sociais, principalmente, aquelas delimitadas pela família - na figura dos pais- e pela escola - na figura do professor. Os resultados do presente estudo apontam isso: os jovens que apresentaram maior pontuação correlacional na identidade com os pares sócio-normativos (pai, mãe e professores) o fizeram também, negativamente, nas condutas anti-sociais e delitivas. Sendo assim, o compromisso e adesão a esses pares normativos não somente é importante, justamente por serem agentes funcionais para transmitir valores e formar traços de personalidade (OMAR; FORMIGA; URIBE; SAMPAIO, 2004; LOEHLIN, 1997), construtos esses, que ocorrem na socialização entre eles, sendo promotores de uma adolescência auto-consciente, humana e com tendência as condutas de apoio social a outros jovens.

As condutas desviantes, no presente estudo, seria um reflexo da debilidade dos limites convencionais, principalmente, quando se trata do afastamento do vínculo afetivo. condição essa que pode ser entendido como a falta de comprometimento com os pares tradicionais e suas forças socializadoras para um comportamento socialmente aceito e a adesão débil aos papéis sociais convencionais direcionados por esses pares (professores, família, e especialmente, os pais) objetivando tanto uma melhor formação quanto fator de proteção social e psicológica. Essa convencionalidade ocorreria apenas se estivessem envolvidos escola e família numa união que buscassem a promoção de melhores oportunidades de engajamento desses jovens em atividades socializadoras de esclarecimento e formação do valor das outras pessoas e seus impactos psicossociais.

Desta maneira, fomentar entre pais, filhos e professores uma forte ligação afetiva, é investir no desenvolvimento de habilidades sociais a tríade professores- 
jovens-pais a fim de instituir um fator de proteção e de identificação contra o desvio comportamental de algum jovem quanto manifestado seja em sala de aula, sejam, em sua própria casa, junto a família. Vale destacar que não se trata de controle excessivo e perda da expansão de conduta dos jovens, mas, poder acompanhá-los individual e interpessoal na sua dinâmica psicossocial. É bem possível, que a partir do grau de identidade dos jovens em relação a estes pares, a responsabilidade de ambas as instituições poderiam ser mais adequadas, utilizando mais do diálogo e conscientização de suas atitudes do que as imposições e castigos quando uma norma ou regra social é rompida.

Seguir a direção desses achados, não somente teria efeito positivo na orientação escolar, bem como, nas práticas parentais da família autoritativa e indulgência do que de permissividade e negligência (FORMIGA; OLIVEIRA; CURADO; LÜDKE; TEIXEIRA; FACHINI, 2003; MULVEY; CAUFFMAN, 2001); essas últimas quando não esclarecidas e centradas na rigidez comportamental como controle da vida do filho pode desencadear, possivelmente, maltrato e relação paisjovens e professores-jovens inadequados, levando o jovem a conversar apenas pelo fato de não sofrer o castigo ou não se dirigir a eles porque parece já saber o que ele vai falar (discurso de que ele estar errado, que sempre faz as coisas se prestar atenção, que não é "perfeito", etc.) ao invés de promover uma auto-conscientização e atualização dos direitos e deveres que cada um precisa seguir (FORMIGA, 2005).

Assim, quando os adolescentes não se sentem envolvidos ou comprometidos com a instituição a qual fazem parte ou as pessoas que a compõem, neste caso, a família e a escola, não encontrando apoio emocional e social, estes jovens não serão capazes de internalizar valores, padrões convencionais, habilidades sociais maduras. Assim como, não serão capazes de organizar-se em termos de traços de personalidade que contribua para um comportamento segundo as normas sociais vigentes. A explicação dos comportamentos desviantes a partir da identidade com os pares sócio-normativos vem assegurar o grande valor e a influência que família e escola venham ter na formação e estratégias dos comportamentos dos jovens em nossa sociedade, focalizando com isso, atividade preventiva onde não se observe apenas o jovem, mas, todo o seu entorno sóciohumano. 
Ao considerar esses resultados, além de corroborar o estudo de Formiga (2005), aponta-se em direção de programas de intervenção que enfatize a formação da conduta juvenil socialmente desejável a partir da dinâmica família e escola. Não se trata de torná-los jovens rígidos as normas e obrigações das autoridades familiares e escolares, conduzindo-os numa espécie de dogmas e crenças comportamentais, mas, apontar em direção da confrontação sobre a dissonância das condutas tangenciadores das normas e o prejuízo psicossocial, já que esses jovens se encontram, devido a construção social sobre os direitos da permissividade adolescente, predispostos a romperem com o que the proibido devido ao seu estado de excessiva busca de novidades e sensações, os quais, geralmente, convergem a esse tipo de conduta. Além de considerá-la como originada das diferenças individuais, também, se estrutura a partir do processo socializador.

Finalmente, no presente estudo buscou-se avaliar a relação entre pares sócio-normativos e conduta desviante em diferentes amostras espera-se que tenha sido atendido. Porém, apesar dos resultados serem satisfatórios alguns limites merece ser destacados: seria interessante um estudo sobre essas variáveis em termos de famílias estruturadas, reestruturadas e monoparentais; outro estudo poderia ser direcionado em termos da comparação das respostas dos jovens de instituições coercitivas com os da população geral em relação às identidades sócionormativas; por fim, seria útil um estudo intercultural e transcultural com o objetivo de avaliar as relações entre as variáveis em questão.

Contudo, é bom destacar que quando for considerar os resultados deste estudo é necessário ter em conta os aspectos mais específicos ou universais de cada cultura na avaliação das variáveis quando se pretender adaptá-las para outros contextos. Por um lado é importante considerar as dimensões locais, específicas ou exclusivas (emics) da orientação de cada cultura, bem como, e não menos importante, avaliar as dimensões universais (etics) da Cultura, com o objetivo de compara os construtos estudados aqui para outro espaço geo-político e social. (MUENJOHN; ARMSTRONG, 2007; TRIANDIS et al., 1993; TRIANDIS, 1994; VAN DE VIJVER; LEUNG, 1997). 


\section{REFERÊNCIAS}

AGÜERO, A. J. El transtorno de conducta en la infancia como precursor del trastorno antisocial del adulto. Estudios de seguimiento a medio y largo plazo. Necesidad de programas preventivos. Revista Electrónica de Psiquiatria, v. 2, p. 1-9. 1998.

ARIÉS, P. História social da criança e da família. Rio de Janeiro: Guanabara. 1981.

AVELLAR, A. P. Rompimento familiar e delinqüência juvenil: Quais as possíveis conexões? Revista eletrônica de ciências sociais, n.1, v.1, pp.181-200. 2007.

BATES, K. A.; BADER, C. D.; MENCKEN, F. C. (2003). Family Structure, PowerControl Theory, and Deviance: Extending Power-control Theory to Include Alternate Family Forms. Western Criminology Review v. 4, n. 3, pp. 170-190. 2003.

BEE, H. O ciclo vital. Porto Alegre: Artes Médicas. 1997.

BOLSONI-SILVA, A. T.; MARTURANO, E. M. Práticas educativas e problemas de comportamento: Uma análise a luz das habilidades sociais. Estudos de psicologia, v. 7 n. 2, pp. 227-235. 2002.

BRENNER, V.; FOX, R. Parental discipline and behavior problems in young children. The journal of genetic psychology, v. 159. n. 2, pp. 251-256. 1998.

BRONFENBRENNER, U. A ecologia do desenvolvimento humano: experimentos naturais e planejados. Porto Alegre: Artmed. 1994/1996.

BUCETA, L. F. Teorías y delinquência juvenil. Revista de ciencias sociales, v. 15, pp. 243-253. 2000.

BYRNE, B. M. A primer of LISREL: Basic applications and programming for confirmatory factor analytic models. New York: Springer-Verlag. 1989.

DOMINGUES, J. M. As formas fundamentais da solidariedade contemporânea. Em: Interpretando a modernidade: Imaginário e instituições. Rio de Janeiro: FGV. 2002. p. 191-222.

ESPINOSA, P. Razonamiento moral y conducta social en el menor. Tese de Doutorado. Universidade da Coruña, Espanha. 2000.

FORMIGA, N. S. Comprovando a hipótese do compromisso convencional: Influência dos pares sócio-normativos sobre as condutas desviantes em jovens. Revista psicologia ciência e profissão, v. 25, n. 4, pp. 602-613. 2005. 
FORMIGA, N. S. Condutas anti-sociais e delitivas: Uma explicação em termos dos valores humanos. Dissertação (Mestrado em psicologia). Universidade federal da Paraíba, João Pessoa. 2002.

FORMIGA, N. S. Fidedignidade da escala de condutas anti-sociais e delitivas ao contexto brasileiro. Revista Psicologia em Estudo, v.8, n.2, p.133-138, 2003.

FORMIGA, N. S. Um estudo intracultural dos indicadores da relação familiar. Revista de psicologia da vetor editora, v. 5, n.1, pp. 66-71. 2004.

FORMIGA, N. S.; FACHINI, A. C. Apoio social e condutas desviantes: Um estudo sobre a consistência explicativa dos grupos cotidianos no comportamento dos jovens. III Congresso Científico do Ceulp-Ulbra. Mercado e cidadania: O papel da Universidade. 21 a 22 de maio. Palmas-TO. 2003. [Resumos]. p. 186-188.

FORMIGA, N. S.; FACHINI, A. C.; CURADO, F.; TEIXEIRA, J. Fatores de proteção das condutas anti-sociais e delitivas In: IV jornada de iniciação científica do CEULP-ULBRA, 2004, Palmas-TO. p.368-369

FORMIGA, N. S.; GOUVEIA, V. V. Adaptação e validação da escala de condutas anti-sociais e delitivas ao contexto brasileiro. Revista Psico, v. 34, n. 2, pp. 367-388. 2003.

FORMIGA, N. S.; GOUVEIA, V. V.; VASCONCELOS, T. C.; ANDRADE, J. M.; SANTOS, W. S.; PIMENTEL, C. E. Relação entre as práticas parentais e os valores humanos em jovens do ensino fundamental. III congresso norte-nordeste de psicologia. Construindo a psicologia brasileira: Desafios da ciência e prática psicológica, João Pessoa: PB. 27 a 31 de maio. 2003. [Resumos]. p. 350.

FORMIGA, N. S.; OLIVEIRA, A. R. N.; YEPES, C.; ALVES, I. Explicando as condutas anti-sociais e delitivas a partir da busca de intensidade e novidade em jovens. I congresso latino-americano de psicologia. São Paulo: União latinoamericana de entidades de psicologia. 2005.

FORMIGA, N. S; OLIVEIRA, A. R. N.; CURADO, F.; LÜDKE, L.; TEIXEIRA, J.; FACHINI, A. C. Estratégias educativas na família e condutas anti-sociais e delitivas. Em: XXXIII Reunião anual da sociedade brasileira de psicologia. Psicologia: Compromisso com a vida. Belo Horizonte - MG: Sociedade Brasileira de Psicologia; 2003, [Resumos]. p. 383.

GROSSI, F. J.; PAÍNO, S. G.; FERNÁNDEZ, J. A.; RODRÍGUEZ, F. J.; HERRERO, F. J. Conducta Delictiva y Ámbito Familiar. Endereço da Página WEB:

http://www.uniovi.es/ Psi/REIPS/v1n1/articulo9.html. (Consultado em 15 de Outubro 2004). 2000. 
INDEX PSI. Família, organização, conduta, jovens e Conduta, jovens, família, estrutura e família, sociedade e delinqüência. Endereço da Página WEB: http://www.Indexpsi.org.br (Consultado em 10 de Novembro). 2008

LOEHLIN, J. C. A test of J. R. Harris's Theory of peer influences on personality. Journal of personality and social psychology, v. 72, n. 5, pp. 1197-1201. 1997.

MOLINA, A. G-P.; GOMES, L. F. Criminologia: Introdução a seus fundamentos teóricos. São Paulo, SP: Editora Revista dos Tribunais. 1997.

MUENJOHN, N.; ARMSTRONG, A. Transformational Leadership: The Influence of Culture on the Leadership Behaviours of Expatriate Managers. International Journal of Business and Information, v. 2, n. 2, pp. 265-283. 2007.

MULVEY, E. P.; CAUFFMAN, E. The inherent limits of predicting school violence. American psychologist, v. 56, n. 10, pp. 797-802. 2001.

MUÑOZ, G. J. J. Factores de riesgo y protección para la conducta antisocial en adolescentes. Revista de psiquiatria da faculdade de Barna, v. 31, n. 1, pp. 21-37. 2004.

MUÑOZ, G. J. J.; NAVAS, E. C.; GRAÑA G. J. L. Factores psicológicos de riesgo y protección para la conducta antisocial en adolescentes. Actas Espanhola de psiquiatria, v. 33, n. 6, pp. 366-373. 2005.

MUÑOZ-RIVAS, M.; GRAÑA, J. L. L. Factores familiares de riesgo y de protección para el consumo de drogas en adolescentes. Psicothema, v. 13, n. 1, pp. 87-94. 2002.

OMAR, A.; FORMIGA, N. S.; URIBE, H. D.; LÜDKE, L. Correlatos entre el medio ambiente familiar y el desempeño académico en adolescentes argentinos e brasileros. XXXIII Reunião anual da sociedade brasileira de psicologia.

Psicologia: Compromisso com a vida, Belo Horizonte - MG. 22 a 26 de Outubro. 2003. [Resumos]. p. 351.

OMAR, A; FORMIGA, N. S.; DELGADO, H. U.; SAMPAIO, M. La impacto de la personalidad sobre la autoimagen y la valoración de las figuras modeladoras en adolescentes escolares. Em: V congresso Internacional de Educação. Os desafios no processo de ensino-aprendizagem. São Luis - MA: Educare, 2004. p. 390.

OUTEIRAL, J. O. Adolescer: Estudos sobre adolescência. Porto Alegre: Artes Médicas. 1994

RODRÍGUEZ, A.; TORRENTE, G. Interacción familiar y conducta antisocial. Boletín de Psicología, v. 78, pp. 7-19. 2003. 
SCIELO. Família, organização, conduta, jovens e Conduta, jovens, família, estrutura e família, sociedade e delinqüência. Endereço da Página WEB: http://www.scielo.br (Consultado em 10 de Novembro). 2008

SCHNEIDER, J. O. Transmissão de valores de pais para filhos: Dimensões do desejável e do perceptível. Dissertação (Mestrado em Psicologia). Universidade Federal da Paraíba, João Pessoa. 2001.

SEISDEDOS, N. C. Cuestionario A - D de conductas antisociais - delictivas. Madri: TEA. 1988.

STOFF, D. M.; BREILING, J.; MASER, J. D. Handbook of antisocial behavior. Canada: John Wiley and songs. 1997.

SUKHODOLSKY, D. G.; COLUB, A. G.; CROMWELL, E. N. Development and validation of the anger rumination scale. Personality and individual differences, $v$. 31, pp. 689-700. 2001

TABACHNICK, B. G.; FIDELL, L. S. Using multivariate statistics. Needham Heights, MA: Allyn \& Bacon.1996.

TORRENTE H. G.; RODRÍGUEZ G. Á. Precedentes sociofamiliares de la conducta antisocial. Em: A. O. Bernal; M. V. M. Jiménez \& P. V.i Elias (Eds.), Aplicaciones en psicología social. Madri: Biblioteca Nueva. 2000. pp. 197-202.

TRIANDIS, H. C. Individualism and collectivism. Boulder, CO: Westview Press. 1995.

TRIANIS, H. C. et all. An etic-emic analysis of individualism and collectivims. Journal of cross-cultural psychology, v. 24, n. 3, pp. 366-383. 1993.

VAN DE VIJVER, F. \& LEUNG, K. Methods and data analysis for cross-cultural research. Thousand Oaks, CA: Sage Publications. 1997.

VILLAR, P. T.; LUENGO, M. A. M.; GÓMEZ, J. A. F.; ROMERO, E. T. Una propuesta de avaliación de variables familiares en la prevención de la conducta problema en la adolescencia. Revista psicothema, v. 15, n. 4, p. 581-588. 2003. 